\title{
A PRESENÇA DAS MULHERES E SUA REPRESENTATIVIDADE EM CARGOS DE LIDERANÇA
}

\author{
Carla Roberta Marques Felix ${ }^{25}$ \\ Sidney Verginio da Silva ${ }^{26}$
}

RESUMO: O presente artigo tem como objetivo abordar um tema que se tornou essencial para o desenvolvimento das empresas e da sociedade: a presença das mulheres e sua representatividade em cargos de liderança. Vive-se em uma era onde tem sido recorrente deixar-se de lado o antigo estereótipo de que determinado curso e profissão só deve ser exercido por homens. A cultura vem mudando e com ela, em especial as novas gerações, já compreendem que a igualdade é um direito e os velhos padrões já não são aceitáveis, sendo que as mulheres vêm procurando frequentemente cursos e profissões voltadas a engenharia e tecnologia. De acordo com o RAIS 2018, citado por Camargo et al., no Brasil a porcentagem de participação das mulheres no mercado de trabalho subiu, em 2018, $3,91 \%$ em relação ao ano anterior, número maior do que o aumento de participação dos homens. $O$ estudo demonstrou que, no tocante ao tema representatividade feminina dentro das empresas, o Brasil, apesar de já apresentar empresas que criaram programas de inclusão, os números ainda são insatisfatórios, expondo dessa forma que o país ainda tem um longo caminho a percorrer para alcançar um equilíbrio representativo de gêneros dentro das empresas.

Palavras-chave: Representatividade. Mulheres. Liderança.

\section{INTRODUÇÃO}

Muito se fala, no atual cenário global, sobre inclusão e igualdade de gênero dentro das grandes empresas. O mundo vive um processo de globalização desde meados dos anos 90, Em que o fator tecnológico, apesar de primariamente difundido, não foi o único a ser inserido na sociedade como um todo. A era da informação e dos países multiculturais se faz presente e, com ela cada vez mais presente, surge o questionamento quanto ao papel da mulher na sociedade e à divisão sexual dentro do ambiente empresarial.

Proni e Proni (2018, p. 01) dizem que:

As mulheres estão presentes em quase todas as profissões, inclusive em atividades antes destinadas apenas aos homens. Além de superar a segregação ocupacional, um número crescente de mulheres vem conquistando respeito profissional e alcançando cargos de chefia e comando.

Condizente com a afirmação dos autores aludidos, a Época Negócios (2019) expôs, dentro de uma pesquisa realizada com 165 grandes empresas presentes no Brasil, que 65\% delas monitoram a proporção entre homens e mulheres contratados e 54\% das organizações que participaram da pesquisa disseram contratar mais mulheres do que homens para cargos de maior nível hierárquico.

De acordo com o RAIS (2018, apud CAMARGO et al., 2018, p. 52), afirma-se que o crescimento da participação feminina no mercado de trabalho vem sofrendo mudanças significativas. Em um recorte por gênero, os dados mostraram que, no ano de 2018, o nível de emprego da mão de obra feminina cresceu 3,91\% em comparação com 2,57\% dos homens.

\footnotetext{
${ }^{25}$ Graduada em Administração de Empresas, cursando MBA em Gestão Estratégica e Inteligência de Negócios. carlarmfelix@gmail.com

${ }^{26}$ Orientador. Mestre em Administração, MBA em Gestão de Tecnologia da Informação e Bacharel em Sistemas de Informação.orientadorsidney@unis.edu.br
} 
Apesar dos números apresentados pela pesquisa acima mencionada, a ocupação por parte dos homens em cargos de gerência e diretoria ainda é grande. De acordo com o IBGE (2018), em levantamento feito referente ao ano de 2016, ainda que o número de mulheres em cargos de liderança tenha aumentado, 60,9\% dos cargos gerenciais ainda eram ocupados pelos homens, contra $39,1 \%$ de mulheres ocupando tais cargos.

Vive-se também em uma época em que as redes sociais transformaram-se na principal ferramenta de disseminação de assuntos, opiniões, debates etc. A ponte entre empresas e pessoas ficou mais estreita e, com isso, através da cultura das novas gerações em conjunto com os próprios objetivos da ONU (Organização das Nações Unidas) de alcançar a igualdade de gênero e empoderar todas as mulheres e meninas, o assunto toma uma nova proporção. Como variáveis que influenciam diretamente a economia, é esperado hoje das empresas um papel ativo no que tange ao incentivo de programas de representatividade, que busquem levar o país a um cenário onde de fato existam números expressivos e reconhecimento da capacidade profissional de mulheres dentro dos ambientes empresariais da mesma forma como acontece com homens.

O trabalho tem como propósito, por meio de uma revisão bibliográfica, explorar a problemática da igualdade de gêneros em cargos de liderança, fazendo-se entender quais os impactos do incentivo a representatividade e como as empresas estão lidando com tal demanda.

Representatividade feminina dentro das organizações é um tema de extrema importância, pois fica claro o fato de que, apesar de muito se falar em igualdade, a realidade não se encontra com a teoria de que as mulheres conseguiram alcançar um estado de equilíbrio na sociedade. A participação de homens e mulheres no mercado não é igualitária, estudos mostram que mulheres trabalham o dobro do tempo e ganham menos do que os homens na mesma função.

O número de pesquisas feitas cujo tema abordado e a real participação da mulher no mercado de trabalho e não apenas a participação, mas a ocupação de cargos de liderança, mostra que o tema, apesar de difundido, ainda se encontra em uma fase inicial quando se fala em ações por parte das organizações.

O presente artigo tem sua importância pois o tema proposto constrói uma estrutura que está cada vez mais forte no país, fazendo com que as empresas possam investir em programas de inclusão e incentivo para que mais mulheres ingressem no mercado de trabalho e ocupem cargos nos altos níveis da hierarquia.

\section{METODOLOGIA}

Bruyne (1991, apud OLIVEIRA, 2011) diz que a metodologia deve ajudar a explicar não apenas os produtos da investigação científica, mas principalmente seu próprio processo, pois suas exigências não são de submissão estrita a procedimentos rígidos, mas antes da fecundidade na produção de resultados.

O presente artigo se apresenta como pesquisa bibliográfica. A estruturação do trabalho se deu através de artigos, relatórios e portais dispostos online na internet.

\section{REVISÃO DE LITERATURA}

\subsection{IGUALDADE DE GÊNERO}

Sabe-se que, contrário à definição, existe ainda uma grande separação resultante de estereótipos, tendo como um exemplo muito comum o caso das engenharias como profissão no 
país. Os cursos de engenharia vêm, ao longo dos últimos anos, ganhando mais representatividade, mas por muitos ainda são considerados cursos "para homens".

De acordo com definição do Portal Geledés (2017):

Também conhecida como igualdade sexual, esta é considerada a base para a construção de uma sociedade livre de preconceitos e discriminações. Homens e mulheres devem ser livres para fazer as suas escolhas e desenvolver as suas capacidades pessoais sem a interferência ou limitação de estereótipos.

Os números expostos pelo CONFEA (2019) mostram a discrepância no setor de engenharia quando se é levado em conta a representatividade das mulheres, como mostra a Tabela 1:

Tabela 1 - Diferença entre homens e mulheres na engenharia de acordo com registros do CREA por estado em 2019

\begin{tabular}{|l|c|c|c|}
\cline { 2 - 4 } \multicolumn{1}{c|}{} & HOMENS & MULHERES & DIFERENÇA \% \\
\hline CREA-AC & 1.782 & 627 & $284,21 \%$ \\
\hline CREA-AL & 6.484 & 1.127 & $575,33 \%$ \\
\hline CREA-AM & 10.576 & 3.517 & $300,71 \%$ \\
\hline CREA-AP & 847 & 196 & $432,14 \%$ \\
\hline CREA-BA & 37.623 & 10.129 & $371,44 \%$ \\
\hline CREA-CE & 16.411 & 3.341 & $491,20 \%$ \\
\hline CREA-DF & 14.846 & 3.337 & $444,89 \%$ \\
\hline CREA-ES & 13.915 & 3.859 & $360,59 \%$ \\
\hline CREA-GO & 24.649 & 6.098 & $404,21 \%$ \\
\hline CREA-MA & 9.804 & 2.646 & $370,52 \%$ \\
\hline CREA-MG & 107.554 & 24.664 & $436,08 \%$ \\
\hline CREA-MS & 11.400 & 2.723 & $418,66 \%$ \\
\hline CREA-MT & 18.324 & 4.954 & $369,88 \%$ \\
\hline CREA-PA & 20.388 & 7.292 & $279,59 \%$ \\
\hline CREA-PB & 8.433 & 1.905 & $442,68 \%$ \\
\hline CREA-PE & 20.607 & 4.915 & $419,27 \%$ \\
\hline CREA-PI & 6.035 & 1.164 & $518,47 \%$ \\
\hline CREA-PR & 50.350 & 10.293 & $489,17 \%$ \\
\hline CREA-RJ & 75.061 & 16.272 & $461,29 \%$ \\
\hline CREA-RN & 10.592 & 2.932 & $361,26 \%$ \\
\hline CREA-RO & 4.086 & 1.419 & $287,95 \%$ \\
\hline CREA-RR & 821 & 400 & $205,25 \%$ \\
\hline CREA-RS & 58.817 & 11.600 & $507,04 \%$ \\
\hline CREA-SC & 35.042 & 8.084 & $433,47 \%$ \\
\hline CREA-SE & 4.847 & 1.396 & $347,21 \%$ \\
\hline & & & \\
\hline
\end{tabular}

Fonte: Adaptado de CONFEA, 2019. 
Como mostram os dados do CONFEA de 2019, o setor de engenharia no país ainda sofre com uma diferença substancial quanto ao número de engenheiros registrados por gênero. $\mathrm{O}$ estado com a menor diferença registrada foi o de Roraima, onde existem 205,25\% mais engenheiros homens do que mulheres.

Os processos de socialização reforçam os preconceitos e estereótipos do gênero como próprios de uma hipotética natureza feminina e masculina, com fundamento, especialmente, numa determinação biológica: a diferença biológica transmuta-se em desigualdade social e assume uma aparência de naturalidade. A noção de gênero assume um duplo caráter epistemológico. De um lado, opera como categoria descritiva da realidade social, que possibilita nova visibilidade às mulheres, direcionada às variadas formas de discriminação e opressão, e, de outro, afirma-se como categoria analítica, como um novo modelo para compreensão dos fenômenos sociais. (CARLOTO, 1998, apud LIMA, 2018, p. 104).

Scott (2016 Apud LIMA, 2018, 104) complementa afirmando que o mundo do trabalho não está imune à naturalização da desigualdade sexual, razão essa que demarca a necessidade de uma compreensão sistemática do tema.

Ademais, para Scott (2016 Apud LIMA, 2018, 104), "o mercado de trabalho sexualmente segregado faz parte do processo de construção do gênero".

O que é realmente praticado no Brasil em termos de igualdade de gênero está longe de ser um resultado satisfatório, porém vale destacar que grandes empresas já buscam projetos próprios de inclusão das mulheres no mercado de trabalho, e outras já têm como será exemplificado em capítulos posteriores do artigo.

\subsection{MULHERES EM CARGOS DE LIDERANÇA}

Ainda que as empresas venham dando pequenos passos em direção a igualdade nas oportunidades profissionais para mulheres e que algumas empresas já mostrem números representativos de líderes mulheres, o caminho a percorrer ainda é grande e como se não bastasse a dificuldade das mulheres em adentrarem no mercado, existem barreiras sólidas quanto a seu crescimento profissional dentro das empresas.

$\operatorname{Vaz}(2013$, p. 12) afirma que

No Brasil, de fato, ainda são raras as mulheres em altos cargos corporativos. Entre os funcionários e dirigentes de uma amostra de organizações extraída do grupo das 500 maiores empresas no país, por exemplo, observa-se um "afunilamento hierárquico", ou seja, a incidência de menos mulheres quanto mais elevada é a instância de poder, ainda que o grau de instrução feminino seja superior ao masculino em todos os níveis considerados. Assim, se elas representavam 35\% dos funcionários sem atribuições de comando, em 2007, no quadro executivo (presidente, vicepresidentes e diretores) esse percentual reduzia-se a 11,5\%.

Uma das razões exploradas por diversos autores é chamada de efeito "teto de vidro". Olinto (2011) conceitua teto de vidro como um tipo de segregação que faz com que as mulheres não 
progridam em seus ambientes de trabalho e mantenham posições mais subordinadas do que os homens, principalmente nas carreiras de ciências e tecnologia. (CAMARGO et al, 2019, p. 55).

As mulheres passam por diversas dificuldades ao longo de suas carreiras, mas como destaca Silva et al (2017, p. 32) [...] "buscam superar esses entraves com garra e espírito competitivo e, ao conquistar o mercado de trabalho, têm sua independência financeira, tornam-se participativas econômica e socialmente" [...].

Para Toni (2011, apud SILVA et al, 2017, p. 06):

O grande número de mulheres nos cargos de comando, atualmente, se explica pela forte pressão que elas exercem para ocupar seu espaço e pelo próprio mercado de trabalho, que já enxerga a mulher com um estilo estratégico de exercer a liderança, pois elas estudam mais, se dedicam mais e, normalmente, estão mais bem preparadas em processos de seleção, sendo mais transparentes nas dinâmicas e entrevistas.

Mundialmente, Nolan et al (2016 Apud OLIVEIRA; WOIDA, 2018, p. 05), através de pesquisa, expôs que dentro de 21.980 empresas de 91 países, apenas $5 \%$ têm mulheres como diretoras executivas (CEO), porém 60\% dessas empresas contam com mulheres como membros dos conselhos administrativos.

Com resultados mais atuais, o relatório da Grant Thornton, Women in Business: Construindo um plano de ação (2019), mostra um fato interessante a respeito da representatividade. Em países onde os níveis de diversidades são maiores (América Latina), apenas $25 \%$ das empresas tem mulheres em cargos de liderança.

A pesquisa ainda afirma que de um modo geral a liderança feminina vêm crescendo pelo mundo, apesar de destacar a lentidão da evolução. No ano de 2019, segundo a pesquisa, $29 \%$ de mulheres em cargos de liderança se comparado a $24 \%$ do ano de 2018.

A Figura 1 mostra a evolução, desde o ano de 2012, da participação das mulheres em cargos de liderança pelo mundo:

Figura 1 - Proporção de Mulheres em Cargos de Liderança Mundialmente em 2019

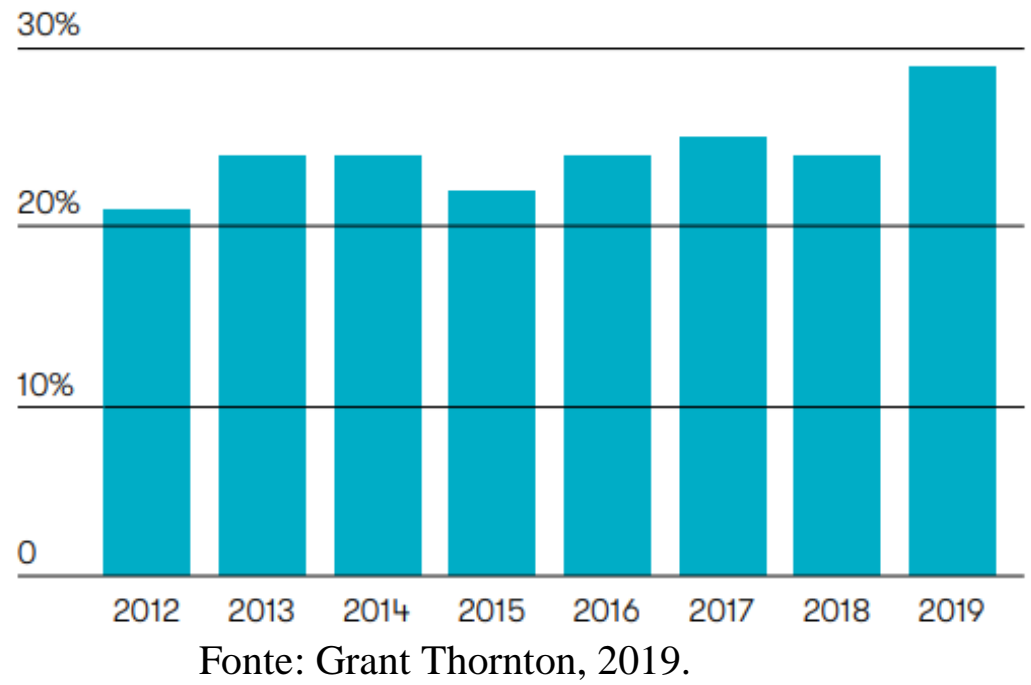


Já a Figura 2 mostra o nível de representatividade feminina em cargos de liderança no Brasil de 2013 a 2019:

Figura 2 - Representatividade feminina ainda é baixa em 2019

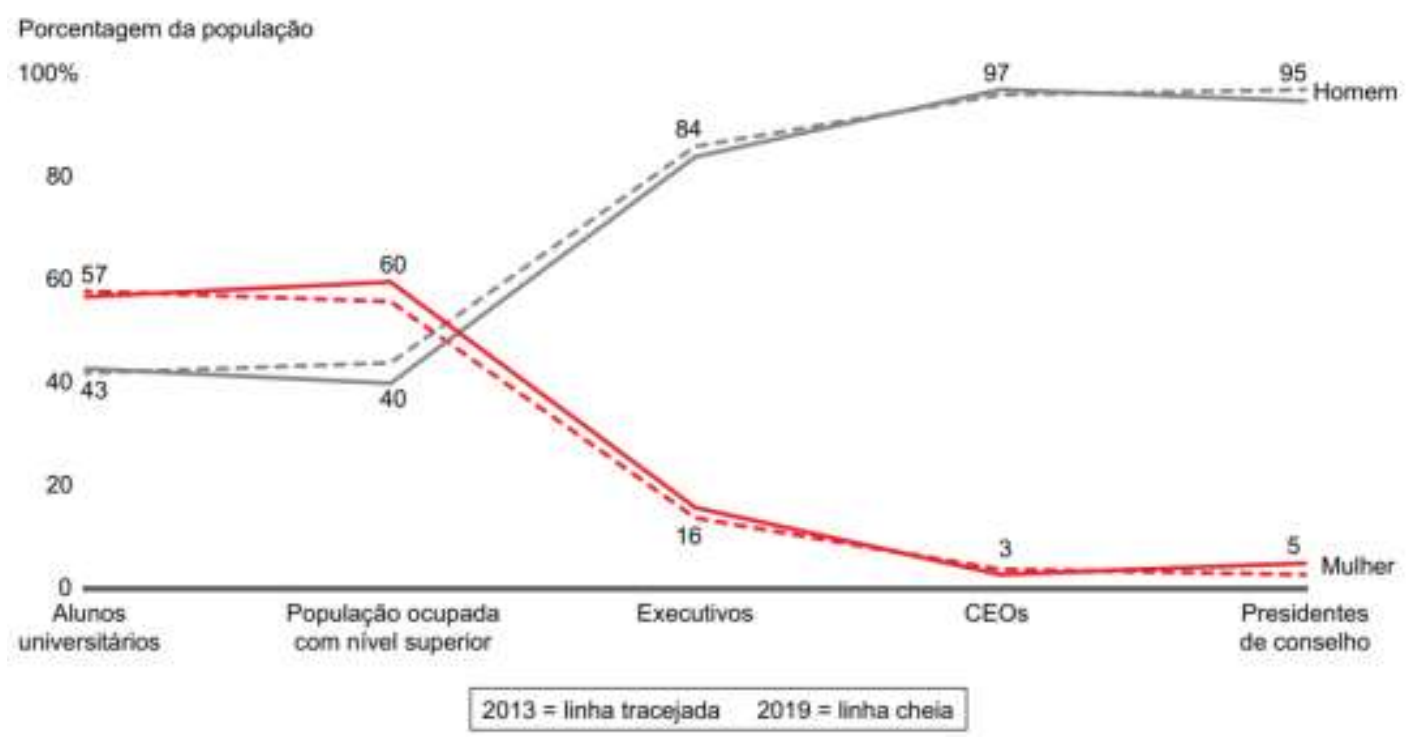

Fonte: Mattos, 2019.

A representação do gráfico acima mostra que as mulheres continuam representando a maioria em se tratando de profissionais que estão cursando ou já concluíram o ensino superior. Dentro do nível estratégico das empresas, no entanto, quanto maior hierarquicamente é a posição, menos participação as mulheres ainda têm. Apesar do número de mulheres que são alunas ou já concluíram o ensino superior ter crescido, os homens estão $90 \%$ à frente delas em se tratando de participação em cargos de nível hierárquico.

\subsection{EMPRESAS QUE PRATICAM A INCLUSÃO E INCENTIVAM A IGUALDADE DE GÊNERO}

A intenção ao se buscar uma participação igualitária dos gêneros nas empresas não é firmar que as mulheres têm maior capacidade de liderança do que os homens, porém, devido às barreiras sofridas pelas mesmas no que se refere a todo o processo, desde o estudo até a busca pelas oportunidades, é realidade que como resultado da dificuldade mulheres estudam mais, se preparam mais, desenvolvem habilidades e criam perfis de liderança tão forte quanto o dos homens.

As mulheres, em sua maioria, são profissionais atentas aos detalhes de cada situação, fazendo com que elas tenham uma visão ampla da empresa. Em função de suas características pessoais, costumam ser bem sucedidas nos processos de comunicação e de negociação. Por terem uma jornada dupla de trabalho (aquele exercido no emprego e aquele dentro de casa), as mulheres conseguem ser mais flexíveis no ambiente corporativo e ainda fazer diversas atividades ao mesmo tempo. E, usando seu instinto maternal, conseguem obter melhores resultados com as pessoas. (ANDRADE, 2016) 
Grandes empresas, principalmente as que surgiram de uma cultura mais inovadora e empreendedora, comuns em startups, não veem na inclusão uma obrigação, mas uma oportunidade de equilibrar não apenas números, mas o ambiente e ter em mãos decisões mais heterogêneas, vindas de pessoas diferentes, com capacidades e pensamentos diferentes.

Oikawa (2018) afirma que vários estudos demonstraram as vantagens da liderança feminina, tanto na gestão de pessoas, como em melhores resultados.

\subsubsection{Prêmio WEPs (Women's Empowerment Principles)}

O Prêmio Women's Empowerment Principles trata-se de uma iniciativa reconhecida pela ONU (Organização das Nações Unidas), cujo propósito é incentivar e reconhecer os esforços de empresas que promovem a cultura da igualdade de gênero e o empoderamento da mulher no Brasil.

Conforme lista o Anuário Prêmio WEPs Brasil (2016), a segunda edição do prêmio aconteceu e vale mencionar algumas das empresas ganhadoras:

- Medalha de Ouro: Unilever Brasil e Renault Brasil, com exemplo de programa de mentoring desenvolvido pela Renault que resultou em um aumento de $40 \%$ de mulheres sendo promovidas na empresa e o programa "desafiar mulheres ao management" que resultou em um aumento em 50\% de mulheres em cargos de gestão na empresa.

- Medalha de Prata: Petrobras Distribuidora, Accenture do Brasil, Recofarma Indústria do Brasil, Furnas Centrais Elétricas, Schneider Electric Brasil, Dow do Brasil Produtos Químicos, Ernst \& Young Auditores Independentes, Cummins Brasil, IBM Brasil, PWC Brasil e Grupo Boticário.

- Medalha de Bronze: Sodexo, Whirlpool Latin America, Real Grandeza, Dudalina, KPMG, Eletrobras Distribuição Rondônia, SE Supermercados (Grupo Pão de Açúcar) e Eletrobras Eletronorte.

A distribuição do Prêmio WEPs em 2016 mostra que, apesar do país estar apenas no começo para o alcance de resultados satisfatórios da participação das mulheres em cargos de liderança, grandes empresas em território nacional são reconhecidas por seus programas de incentivo.

\section{CONSIDERAÇÕES FINAIS}

O mercado vive uma era de transformações tecnológicas e novas tendências vindas de uma geração de empreendedores mais conscientes de suas responsabilidades sociais como pilar para o desenvolvimento econômico dos países.O Brasil se encontra em uma época de inovações, novos formatos de negócios e grande destaque internacional em se tratando do interesse de empresas multinacionais em investirem no país. Dentro do cenário atual, os fatores que compõem uma economia de qualidade estão cada vez mais focados no desenvolvido social no mercado de trabalho.Conforme pesquisa do IBGE (2018), 51,7\% do total da população é composta por mulheres, mostrando, não como o único motivo, mas um dos, como o desafio das empresas agora é outro. O investimento em programas eficientes de inclusão e igualdade de gêneros dentro das organizações podem afetar diversos âmbitos.Com a grande preocupação do empoderamento 
feminino e desenvolvimento social as empresas que desenvolvem programas de inclusão, olhando pelo lado das vantagens competitivas, está desenvolvendo uma grande força para colocar a empresa em evidência perante os olhos de investidores nacionais e internacionais, pois empresas que não apenas se preocupam, mas promovem ações sociais mostram-se eficientes quanto a sua cultura, expondo para o mercado que estão no caminho certo para o desenvolvimento nos moldes de um mundo mais preocupado com sua população.O presente artigo buscou explorar a problemática da igualdade de gêneros em cargos de liderança, fazendo-se entender quais os impactos do incentivo a representatividade e como as empresas estão lidando com tal demanda. $\mathrm{O}$ trabalho contribui para a discussão da representatividade feminina, mostrando em números o quanto o país, apesar de já ter dado os passos iniciais, ainda precisa se desenvolver em tal quesito, levando ao próximo tema: Quais estratégias as empresas que são referências nacionais em programas de representatividade feminina usam e o que se pode aprender com elas? Tal tema poderá contribuir de forma prática para que empresas, mesmo não sendo multinacionais, possam dar os primeiros passos rumo a um ambiente mais equilibrado.

\section{REFERÊNCIAS}

ANDRADE, Hannah. O Impacto Da Liderança Feminina No Mercado De Trabalho. 2016. Disponível em:< http://177.67.128.65/OJS/index.php/revista/article/view/43/62>. Acesso em: 25 set 2019.

CAMARGO, Francielle; TANNHAUSER, Cláudia; BIEGELMEYER, Uiliam; CAMARGO, Marília Emília; BERNARDI, Flávia; CRACO, Tânia. Relações De Poder Entre Gêneros No Ambiente Organizacional: Uma Análise Da Representação Feminina Nas Empresas De Tecnologia Da Informação (TI) De Porto Alegre - RS. 2019. Disponível em:< http://seer.ufal.br/index.php/cir/article/view/7407/6427>. Acesso em: 25 set 2019. CONFEA. Estatísticas. 2019. Disponível em:<

http://estatistica.confea.org.br:8080/EstatisticaSic/ModEstatistica/Pesquisa.jsp?vw=Sexo>. Acesso em: 25 set 2019. ÉPOCA NEGÓCIOS. As Empresas Com Melhores Práticas Para Promover A Liderança Feminina. 2019. Disponível em:< https://epocanegocios.globo.com/Empresa/noticia/2019/08/empresas-com-melhores-praticas-parapromover-lideranca-feminina.html>. Acesso em: 24 set 2019.

GRANT THORNTON. Women In Business: Construindo um Plano de Ação. 2019. Disponível em:< https://www.grantthornton.com.br/globalassets/1.-member-firms/brazil/6.insights/pdf/gtil-wib-report_grantthornton_br_2019_final.pdf>. Acesso em: 25 set 2019.

IBGE. Estatísticas de Gênero: Indicadores Sociais das Mulheres no Brasil. 2018. Disponível em:< https://biblioteca.ibge.gov.br/visualizacao/livros/liv101551_informativo.pdf>. Acesso em: 24 set 2019. LIMA, Denise. A Negociação Coletiva De Trabalho Como Instrumento Para A Efetivação Da Igualdade De Gênero: Uma Investigação Sobre O Direito Ao Auxílio-Creche Como Prática De Democratização Do Cuidado. 2018. Disponível em:<

https://juslaboris.tst.jus.br/bitstream/handle/20.500.12178/138271/2018_lima_denise_negociacao_coletiva.pdf?sequ ence $=1$ \&is Allowed=y>. Acesso em: 25 set 2019.

MATTOS, Luciana. Sem Atalhos: Transformando o Discurso em Ações Efetivas para Promover a Liderança Feminina. 2019. Disponível em: $<$ https://movimentomulher360.com.br/wp-

content/uploads/2019/07/bain_linkedin_liderancafeminina_sematalhos.pdf>. Acesso em: 25 set 2019.

OLIVEIRA, Beatriz; WOIDA, Luana. O Fenômeno Glass Ceiling E O Acesso À Informação: Estudo Sobre

Barreiras Invisíveis Impostas Às Mulheres No Trabalho. 2018. Disponível em:<

https://periodicos.ufpa.br/index.php/complexitas/article/view/6636/pdf>. Acesso em: 25 set 2019.

OLIVEIRA, Maxwell. Metodologia Científica: Um Manual para a Realização de Pesquisas em Administração.

2011. Disponível em:<https://adm.catalao.ufg.br/up/567/o/Manual_de_metodologia_cientifica_-

_Prof_Maxwell.pdf>. Acesso em: 24 set 2019. 
PORTAL GELEDÉS. O Que É Igualdade De Gêneros. 2017. Disponível em:< https://juntas.geledes.org.br/o-quee-igualdade-de-generos/>. Acesso em: 25 set 2019.

PRONI, Thaíssa; PRONI, Marcelo. Discriminação de Gênero em Grandes Empresas no Brasil. 2018. Disponível em:< https://www.jstor.org/stable/90018796?read-now=1\&seq=1\#page_scan_tab_contents>. Acesso em: 24 set 2019.

SILVA, Célia; CARVALHO, Paula; SILVA, Elisangela. Liderança Feminina: A Imagem Da Mulher Atual No Mercado Corporativo Das Organizações Brasileiras. 2017. Disponível em:<

http://uniesp.edu.br/sites/_biblioteca/revistas/20170509163857.pdf>. Acesso em: 25 set 2019. 